\title{
Medidas biométricas obtidas in vivo e na carcaça de ovelhas de descarte em diferentes estágios fisiológicos
}

\author{
Rafael Silvio Bonilha Pinheiro수 ${ }^{1}$ André Mendes Jorge $^{2}$
}

${ }^{1}$ DBZ/FEIS/UNESP - Ilha Solteira, Brasil.

2 DPA/FMVZ/UNESP - Botucatu, SP, Brasil.

RESUMO - Objetivou-se determinar as medidas in vivo e na carcaça de ovelhas de descarte abatidas em diferentes estágios fisiológicos, assim como as possíveis correlações entre essas medidas objetivas (in vivo e na carcaça) e o peso corporal ao abate e da carcaça fria. Foram utilizadas 21 ovelhas da raça Santa Inês, distribuídas nos seguintes estágios fisiológicos: OL = ovelhas mantidas por 60 dias em lactação com seus cordeiros e abatidas um dia após o desmame dos mesmos; OSC = ovelhas que foram mantidas por 60 dias em lactação com seus respectivos cordeiros e mais um período aproximado de 30 dias sem os cordeiros e posteriormente abatidas; e ONP = ovelhas que permaneceram por 60 dias em confinamento e que não pariram durante o ano. Não se observou diferença entre os estágios fisiológicos na maioria das características medidas in vivo e na carcaça. O perímetro da garupa determinado na carcaça e o perímetro torácico, as larguras do peito e da garupa obtidos in vivo mostraram-se altamente correlacionados aos pesos corporal e de carcaça fria dos animais. Portanto, essas medidas podem auxiliar na determinação do peso corporal de ovelhas em diferentes estágios fisiológicos.

Palavras-chave: compacidade da carcaça, correlações, ovino, peso corporal ao abate

\section{Biometric measurements obtained in vivo and in the carcass of culled ewes at different physiological stages}

\begin{abstract}
The objective was to determine in vivo and carcass measurements of culled ewes slaughtered at different physiological stages and the possible correlations between the objective measurements (in vivo and in the carcass) and the body weight at slaughter and cold carcass weight. Twenty-one Santa Inês ewes were used, placed in the following treatments: $\mathrm{EL}=$ ewes which remained in lactation for 60 days with their respective lambs and slaughtered one day after weaning the lambs; EWL = ewes which remained in lactation for 60 days with their respective lambs and a further period of approximately 30 days without their lambs and, afterwards, slaughtered; and ENP = ewes that remained in feedlot for 60 days and did give birth during the year. No difference was observed between rearing systems in most of the characteristics measured in vivo and in the carcass. The croup perimeter determined in the carcass and the thoracic perimeter and chest and croup width obtained in vivo were highly correlated to the body and cold carcass weights of the ewes in this study. Therefore, these measurements can assist in determining the body weight of ewes at different physiological stages.
\end{abstract}

Key Words: body weight at slaughtering, carcass compactness, correlations, sheep

\section{Introdução}

De acordo com Cunha et al. (1999), as medidas biométricas in vivo apresentam alta correlação com as da carcaça e podem ser utilizadas em conjunto ou isoladamente. O conhecimento das características quantitativas e qualitativas da carcaça ovina é fundamental para as indústrias que processam produtos de origem animal. A determinação desses aspectos para fins experimentais ou práticos pode ser obtida por meio das medidas morfológicas in vivo (Pinheiro et al., 2007) ou pelas medidas na carcaça.
Wood \& Macfie (1980) relataram que o comprimento interno da carcaça de cordeiros é um bom indicativo do peso e das características da carcaça. El Karin et al. (1988) encontraram alta correlação entre o comprimento interno da carcaça com seu peso, assim como a medida de profundidade do tórax de ovinos com o peso da carcaça. Mohamed \& Amin (1997) observaram alta correlação entre o peso corporal e as medidas biométricas em caprinos. Yáñez et al. (2004), ao estudarem cabritos de raça leiteira, com $11 \mathrm{~kg}$ a $35 \mathrm{~kg}$ de peso corporal e com diferentes condições corporais, concluíram que as equações estimadas em relação ao 
perímetro torácico e ao comprimento corporal predizem com precisão o peso em jejum e o peso da carcaça fria destes animais. Entretanto, as informações sobre as medidas in vivo e na carcaça e suas possíveis correlações (altas e baixas) são praticamente inexistentes para ovinos adultos.

As medidas realizadas na carcaça são importantes por si só, pois permitem comparações entre tipos raciais, pesos e idades ao abate, sistemas de alimentação, e pela suas correlações com outras medidas ou com os tecidos constituintes da carcaça, possibilitando estimar suas características (Silva \& Pires, 2000). A raça Santa Inês tem sido muito utilizada no Brasil para produção de carne, por ser adaptada à maioria das regiões brasileiras e apresentar bons resultados de produção e qualidade da carne.

No sistema de produção de carne, a carcaça é o elemento mais importante do animal, porque nela está contida a porção comestível de maior valor comercial (Pires et al., 1999). Em virtude disso, devem ser comparadas suas características para identificar as diferenças entre as raças ovinas, procurando aquelas que produzam melhores carcaças. Algumas medidas da carcaça podem apresentar alta correlação com seu peso e também podem ser utilizadas como indicadores de características de rendimento e qualidade e adotadas em sistemas de classificação de carcaças ovinas; porém, é necessária uma gama de estudos que avaliem as medidas na carcaça e no animal vivo, para se conhecerem qual ou quais medidas são os melhores indicadores de rendimento e qualidade da carcaça.

O objetivo neste trabalho foi conhecer os valores das medidas in vivo e da carcaça de ovelhas de descarte da raça Santa Inês abatidas em diferentes estágios fisiológicos, assim como as possíveis correlações entre essas medidas objetivas (in vivo e na carcaça) e o peso corporal ao abate e da carcaça fria desses animais.

\section{Material e Métodos}

O experimento foi realizado no período de abril a dezembro de 2006 utilizando-se 21 ovelhas de descarte da raça Santa Inês (após um período de estação de monta) de um rebanho comercial na cidade de Jaguariúna, São Paulo. No início do estudo, os animais apresentaram peso corporal médio de aproximadamente $43 \mathrm{~kg}$, com idade média de 6 anos. As fêmeas foram distribuídas nos seguintes estágios fisiológicos: $\mathrm{OL}=$ ovelhas que permaneceram por 60 dias em lactação com seus respectivos cordeiros e abatidas um dia após o desmame dos mesmos; OSC = ovelhas que permaneceram por 60 dias em lactação com seus respectivos cordeiros e mais um período aproximado de 30 dias sem os cordeiros, no intuito de recuperar o peso corporal perdido durante o período de amamentação, e que posteriormente foram abatidas; e ONP = ovelhas que permaneceram por 60 dias juntas das ovelhas do OL e OSC e que não pariram durante o ano. Utilizaram-se sete ovelhas por estágio fisiológico, em um delineamento inteiramente casualizado com três tratamentos e sete repetições.

As ovelhas permaneceram em regime de confinamento em uma instalação coberta com área de solário, alimentação e água à vontade durante todo o período experimental. Todas as ovelhas foram abatidas no mesmo dia, portanto as fêmeas do OSC pariram um mês antes das do OL, e todos os partos foram simples (parição de um cordeiro por ovelha).

A dieta fornecida às ovelhas apresentou relação volumoso:concentrado de 70:30 e foi composta de feno de capim-tifton 85 (Cynodon spp.) como volumoso e concentrado (Tabela 1). Os animais receberam duas refeições diárias, à vontade, às $7 \mathrm{~h}$ e às 16 h, em cocho de madeira que permitiu o acesso simultâneo de todos os animais. Os cordeiros tiveram acesso a comedouro seletivo com concentrado à vontade, no intuito de reduzir o desgaste promovido pelo período de lactação das ovelhas. Todos os animais tiveram acesso a sal comum fornecido em cocho.

Um dia antes do abate das ovelhas, foram realizadas as medidas in vivo com os animais em pé sobre uma superfície plana. Determinaram-se o comprimento corporal (distância entre a articulação cérvico-torácica e a base da cauda), a altura do anterior (distância entre a região da

Tabela 1 - Composições percentual e bromatológica da dieta experimental fornecida as ovelhas (\% MS)

\begin{tabular}{|c|c|}
\hline Composição percentual (\%) & $\overline{(\% \mathrm{MS})}$ \\
\hline Grão de milho moído & 20,88 \\
\hline Farelo de algodão & 7,44 \\
\hline Calcário calcítico & 0,24 \\
\hline Fosfato bicálcico & 0,24 \\
\hline Suplemento mineral ${ }^{1}$ & 1,20 \\
\hline Feno de capim-tifton 85 & 70,00 \\
\hline \multicolumn{2}{|l|}{ Composição bromatológica (\%) } \\
\hline Matéria seca & 89,13 \\
\hline Matéria mineral & 4,97 \\
\hline Proteína bruta & 11,81 \\
\hline Extrato etéreo & 2,12 \\
\hline Fibra em detergente neutro & 58,46 \\
\hline Nitrogênio insolúvel em detergente neutro & 0,29 \\
\hline Fibra em detergente ácido & 30,29 \\
\hline Nitrogênio insolúvel em detergente ácido & 0,14 \\
\hline Lignina & 4,08 \\
\hline
\end{tabular}

R. Bras. Zootec., v.39, n.2, p.440-445, 2010 
cernelha e a extremidade distal do membro anterior), a altura do posterior (distância entre a tuberosidade sacra e a extremidade distal do membro posterior), o perímetro torácico (perímetro tomando-se como base o esterno e a cernelha, passando a fita métrica por trás da paleta), a largura da garupa (distância máxima entre os trocânteres dos fêmures) e a largura do peito (distância entre as faces laterais das articulações escápulo-umerais) das ovelhas, além da compacidade corporal (peso corporal ao abate dividido pelo comprimento corporal do animal).

Antes do abate, as ovelhas foram mantidas em jejum de dieta sólida por aproximadamente 16 horas e posteriormente foram pesadas (peso corporal ao abate). Em seguida, foram insensibilizadas com eletronarcose, quando então foram seccionadas as veias jugulares e as artérias carótidas para sangria.

Após a retirada da pele, da evisceração e retirada das extremidades dos membros e da cabeça, as carcaças foram transferidas para câmara frigorífica a $5{ }^{\circ} \mathrm{C}$ por 24 horas, penduradas pelos tendões do gastrocnêmio, em ganchos apropriados para manter as articulações tarsometatarsianas distanciadas em $17 \mathrm{~cm}$. Posteriormente, as carcaças frias foram pesadas e, em seguida, foram realizadas as medidas morfológicas da carcaça de acordo com o descrito por Sañudo \& Sierra (1986): profundidade do tórax (distância máxima entre o esterno e o dorso da carcaça, realizada com o auxílio de um compasso); comprimento da perna (distância entre o períneo e o bordo anterior da superfície articular tarso metatarsiana, realizada com auxílio de uma fita métrica); comprimento interno da carcaça (distância máxima entre o bordo anterior da sínfise ísquiopubiana e o bordo anterior da primeira costela em seu ponto médio, realizada com auxílio de uma fita métrica); comprimento externo da carcaça (distância entre a base da cauda e a base do pescoço, realizada com auxílio de uma fita métrica); largura da garupa (largura máxima entre os trocânteres de ambos os fêmures, realizada com o auxílio de um compasso); perímetro da garupa (perímetro desta região anatômica, tomando-se como referência os trocânteres de ambos os fêmures); perímetro do tórax (envolvendo o esterno e a cernelha, passando-se a fita métrica por trás da paleta); largura do anterior (largura no nível da cernelha, realizada com o auxílio de um compasso); e largura do tórax (largura máxima da carcaça no nível das costelas, tomada com compasso), além da compacidade da carcaça (peso da carcaça fria dividido pelo comprimento interno da carcaça) e da perna (largura da garupa dividida pelo comprimento da perna).

As comparações de médias dos estágios fisiológicos foram feitas pelo teste Tukey a $5 \%$ de probabilidade e as análises de variância, segundo procedimento do SAS (SAS, 1997). Para o estudo das correlações entre as medidas in vivo e da carcaça, assim como do peso corporal ao abate e do peso da carcaça fria, utilizou-se a correlação de Pearson, segundo procedimento CORR do programa SAS (SAS, 1997).

\section{Resultados e Discussão}

Os valores de comprimento corporal, altura do posterior e do anterior obtidos nas ovelhas foram semelhantes $(\mathrm{P}>0,05)$ entre os estágios fisiológicos, com médias de 70,54; 69,52; e 68,01 cm, respectivamente, o que indica que os animais apresentavam tamanho corporal homogêneo, uma característica muito importante para determinar com acurácia as demais medidas biométricas in vivo e na carcaça nos animais (Tabela 2). A medida da largura do peito não diferiu $(\mathrm{P}>0,05)$ entre os animais nos distintos estágios fisiológicos, com valor médio de 19,95 cm.

A largura da garupa e o perímetro torácico das ovelhas diferiram $(\mathrm{P}<0,01)$ entre os estágios fisiológicos e foram menores para as OL em relação às OSC e ONP, com exceção da largura da garupa, que foi semelhante $(\mathrm{P}>0,05)$ entre as fêmeas OL e ONP, com valor médio de $23,79 \mathrm{~cm}$. As OSC e ONP também apresentaram largura da garupa semelhante

Tabela 2 - Medidas objetivas in vivo e compacidade corporal em ovelhas em diferentes estágios fisiológicos

\begin{tabular}{lccrr}
\hline Variável & \multicolumn{2}{c}{ Estágio fisiológico } & \multirow{2}{*}{ CV (\%) } \\
\cline { 2 - 4 } & OL & OSC & ONP \\
\hline Comprimento corporal (cm) & 70,21 & 70,78 & 70,64 & 0,09 \\
Altura do posterior (cm) & 68,01 & 70,11 & 4,14 \\
Altura do anterior (cm) & 66,13 & 68,94 & 0,2550 \\
Perímetro torácico (cm) & $78,50 \mathrm{~b}$ & $84,28 \mathrm{a}$ & 0,1230 \\
Largura do peito (cm) & 19,10 & 20,24 & 8,45 & 0,0011 \\
Largura da garupa (cm) & $23,08 \mathrm{~b}$ & $25,51 \mathrm{a}$ & 20,52 & 4,57 \\
Compacidade corporal (kg/cm) & $0,52 \mathrm{~b}$ & $0,62 \mathrm{a}$ & $24,51 \mathrm{ab}$ & 5,42 \\
\hline
\end{tabular}

a,b Letras distintas na mesma linha diferem significativamente entre si pelo teste de Tukey a $5 \%$ de probabilidade. OL = ovelhas que permaneceram por 60 dias em lactação com seus respectivos cordeiros e abatidas um dia após o desmame dos mesmos. OSC = ovelhas que permaneceram por 60 dias em lactação com seus respectivos cordeiros e mais aproximadamente 30 dias sem os cordeiros e posteriormente foram abatidas. ONP = ovelhas que permaneceram por 60 dias juntas das ovelhas do OL e OSC e que não pariram durante o ano. 
( $\mathrm{P}>0,05)$, com valor médio de 25,01 cm. Portanto, ovelhas abatidas um dia após o desmame de seu cordeiros (OL) apresentam menor perímetro torácico em relação às ovelhas dos demais estágios fisiológicos (OSC e ONP) e, segundo Santana et al. (2001), essa medida está altamente correlacionada ao peso corporal de ovinos jovens da raça Santa Inês.

Resultados semelhantes ao deste estudo (OL) para o perímetro torácico foram obtidos por Mendonça et al. (2003), ao estudarem a morfologia in vivo de cordeiros da raça Corriedale e Ideal, que observaram valor médio de 77,84 cm. Valores superiores aos deste trabalho (Tabela 2) foram constatados por Azeredo et al. (2006) ao avaliarem a morfologia in vivo de cordeiros aos 120 dias de idade. A largura da garupa indica que valores maiores podem apresentar também maior proporção de músculos do corte da perna, uma característica importante a ser buscada em ovinos destinados ao abate, pois a perna é um dos cortes mais nobres da carcaça, e consequentemente mais valorizados, na espécie ovina.

A compacidade corporal foi semelhante $(\mathrm{P}>0,05)$ entre as ovelhas OSC e ONP $(0,62 \mathrm{~kg} / \mathrm{cm})$; no entanto, os valores foram superiores $(\mathrm{P}<0,01)$ aos obtidos para $\mathrm{OL}$ (Tabela 2) e indicam que as ovelhas OL apresentam menores proporções de músculo e de gordura que as OSC e ONP. Segundo Ensminger (1973), as ovelhas, após o desmame dos seus cordeiros, geralmente encontram-se em condições corporais inadequadas devido ao período de lactação, estágio fisiológico de maior exigência nutricional dos animais.

As medidas da carcaça foram similares $(\mathrm{P}>0,05)$ entre as ovelhas (Tabela 3), com exceção do perímetro da garupa e da largura do anterior $(\mathrm{P}<0,05)$, cujos menores valores foram obtidos nas carcaças das ovelhas OL em comparação às OSC. As ovelhas ONP não diferiram $(\mathrm{P}>0,05)$ dos demais animais (OL e OSC). Valores inferiores para algumas destas medidas na carcaça (Tabela 3 ) foram obtidas por Siqueira \& Fernandes (2000) e Garcia et al. (2003), fato relacionado ao estágio de desenvolvimento dos animais, ou seja, ovinos em crescimento.

Siqueira et al. (2001), ao estudarem a morfometria da carcaça de cordeiras abatidas com $40 \mathrm{~kg}$ de peso corporal, constataram para as medidas de comprimento da perna, largura da garupa, comprimento externo e interno da carcaça valores inferiores aos resultados desta pesquisa (Tabela 3) mesmo apresentando pesos de abate semelhantes ao deste estudo. Fato provavelmente relacionado ao genótipo utilizado, à idade e ao estágio fisiológico do animal no momento do abate. De acordo com Azeredo et al. (2006), a maturidade do animal promove remodelação da morfologia nos ovinos.

A compacidade da carcaça foi semelhante entre as OSC e ONP, com valor médio de $0,28 \mathrm{~kg} / \mathrm{cm}$, superior $(\mathrm{P}<0,01)$ ao valor obtido para as OL (Tabela 3). A compacidade da perna não diferiu $(\mathrm{P}>0,05)$ entre os animais nos distintos estágios fisiológicos, com valor médio de 0,51 $\mathrm{kg} / \mathrm{cm}$. Os valores de compacidade da carcaça e da perna deste estudo (Tabela 3) são superiores aos resultados descritos por Siqueira \& Fernandes (2000), possivelmente porque os autores trabalharam com cordeiros abatidos com 30 a $32 \mathrm{~kg}$ de peso corporal. De acordo com esses autores, o índice de compacidade pode representar uma alternativa para avaliar objetivamente a conformação da carcaça, considerando a relatividade da precisão dos sistemas subjetivos.

As medidas in vivo (comprimento corporal, altura do posterior e do anterior) apresentaram correlação (baixa a media) com a maioria das variáveis estudadas (Tabela 4). As

Tabela 3 - Medidas da carcaça e compacidade da carcaça e da perna de ovelhas de descarte abatidas em diferentes estágios fisiológicos

\begin{tabular}{|c|c|c|c|c|c|}
\hline \multirow[t]{2}{*}{ Variável } & \multicolumn{3}{|c|}{ Estágio fisiológico } & \multirow[t]{2}{*}{ CV (\%) } & \multirow[t]{2}{*}{$\operatorname{Pr}>\mathrm{F}$} \\
\hline & OL & OSC & ONP & & \\
\hline Comprimento externo da carcaça $(\mathrm{cm})$ & 62,28 & 65,85 & 63,85 & 5,09 & 0,1500 \\
\hline Comprimento interno da carcaça $(\mathrm{cm})$ & 64,78 & 68,78 & 66,92 & 5,12 & $0,119 s$ \\
\hline Comprimento da perna $(\mathrm{cm})$ & 52,35 & 50,07 & 49,21 & 12,06 & 0,6166 \\
\hline Perímetro da garupa $(\mathrm{cm})$ & $64,35 b$ & $68,50 a$ & $68,07 a b$ & 4,40 & 0,0323 \\
\hline Largura da garupa $(\mathrm{cm})$ & 25,35 & 26,40 & 26,10 & 6,03 & $0,454 \mathrm{c}$ \\
\hline Largura do tórax $(\mathrm{cm})$ & 24,48 & 26,10 & 25,58 & 7,35 & 0,280 \\
\hline Largura do anterior (cm) & $15,48 \mathrm{~b}$ & $17,00 \mathrm{a}$ & $16,24 \mathrm{ab}$ & 5,98 & $0,030 s$ \\
\hline Profundidade do tórax (cm) & 26,18 & 27,54 & 26,75 & 6,78 & 0,342 \\
\hline Perímetro do tórax (cm) & 71,71 & 75,28 & 74,28 & 6,19 & 0,3423 \\
\hline Compacidade da carcaça $(\mathrm{kg} / \mathrm{cm})$ & $0,23 b$ & $0,27 \mathrm{a}$ & $0,29 a$ & 10,48 & 0,0052 \\
\hline Compacidade da perna $(\mathrm{kg} / \mathrm{cm})$ & 0,49 & 0,52 & 0,53 & 9,49 & 0,2108 \\
\hline
\end{tabular}

a,b,c Letras distintas na mesma linha diferem significativamente entre si pelo teste de Tukey a $5 \%$ de probabilidade. ${ }^{1} \mathrm{CV}$ (\%). $\mathrm{L}=$ ovelhas que permaneceram por 60 dias em lactação com seus respectivos cordeiros e abatidas um dia após o desmame dos mesmos. OSC = ovelhas que permaneceram por 60 dias em lactação com seus respectivos cordeiros e mais um período aproximado de 30 dias sem os cordeiros e posteriormente abatidas. ONP = ovelhas que permaneceram por 60 dias juntas das ovelhas do OL e OSC e que não pariram durante o ano. 
medidas da altura do posterior e do anterior dos animais tiveram alta correlação $(\mathrm{P}<0,01)$ com as medidas da carcaça (perímetro da garupa e do tórax). A medida da altura do posterior do animal é altamente correlacionada com a altura do anterior do mesmo $(0,86)$.

Para o perímetro torácico, largura do peito e da garupa, as medidas in vivo foram altamente correlacionadas $(\mathrm{P}<0,01)$ com o peso corporal ao abate e com o peso de carcaça fria das ovelhas (Tabela 4), resultados que estão de acordo com os descritos por Reis et al. (2004), que, ao avaliarem a estimativa do peso vivo de novilhas mestiças leiteiras a partir de medidas corporais, concluíram que o peso corporal pode ser estimado com acurácia a partir da medida do perímetro torácico, pelo valor obtido de correlação entre estas duas variáveis $(0,94)$. Entre as medidas in vivo, a variável que se correlacionou (alta correlação) o maior número de vezes com as demais medidas analisadas foi o perímetro torácico (Tabela 4), confirmando os resultados de Santana et al. (2001), que também encontraram para a maioria das variáveis determinadas in vivo alta correlação com a medida do perímetro torácico de ovinos jovens da raça Santa Inês.

Com exceção do comprimento da perna e da profundidade do tórax, as demais medidas tomadas na carcaça apresentaram correlação significativa $(\mathrm{P}<0,01)$ com o peso corporal ao abate e de carcaça fria das ovelhas deste estudo; no entanto, o perímetro da garupa foi a medida na carcaça com o maior valor de correlação $(0,83$ e 0,90), assemelhando-se aos valores obtidos para as medidas in vivo (perímetro torácico, largura do peito e da garupa) para estas mesmas variáveis (Tabela 4). Essas medidas com alta correlação podem ser utilizadas para estimar com maior precisão o peso ao abate e da carcaça refrigerada de ovelhas de descarte da raça Santa Inês.

O comprimento da perna determinado na carcaça dos animais experimentais não apresentou correlação $(\mathrm{P}>0,05)$ com as demais medidas avaliadas (Tabela 4). O valor de correlação entre o peso corporal ao abate e o peso de

Tabela 4 - Coeficiente de correlação (r) e probabilidade (P) entre as medidas in vivo e da carcaça e do peso ao abate e da carcaça fria de ovelhas abatidas em diferentes estágios fisiológicos

\begin{tabular}{|c|c|c|c|c|c|c|c|c|c|c|c|c|c|c|c|c|c|}
\hline \multicolumn{2}{|c|}{ Variável } & \multicolumn{6}{|c|}{ Medidas in vivo } & \multicolumn{9}{|c|}{ Medidas na carcaça } & \multirow[b]{2}{*}{ Pcf } \\
\hline & & Cc & Ap & Аа & Pet & $\mathrm{Lp}$ & Lg & Сес & Cic & Сp & $\mathrm{Pg}$ & Lg & Lat & $\mathrm{La}$ & $\mathrm{Pt}$ & Pet & \\
\hline Ap & $\mathrm{P}$ & 0,01 & & & & & & & & & & & & & & & \\
\hline \multirow[t]{2}{*}{ Aa } & $\mathrm{P}$ & 0,09 & 0,01 & & & & & & & & & & & & & & \\
\hline & $\mathrm{r}$ & 0,38 & 0,86 & & & & & & & & & & & & & & \\
\hline Pet & $\mathrm{P}$ & 0,08 & 0,01 & 0,01 & & & & & & & & & & & & & \\
\hline $\mathrm{Lp}$ & $\mathrm{r}$ & 0,23 & 0,49 & 0,53 & 0,81 & & & & & & & & & & & & \\
\hline \multirow[t]{2}{*}{ Lg } & $\mathrm{P}$ & 0,22 & 0,04 & 0,02 & 0,01 & 0,01 & & & & & & & & & & & \\
\hline & $\mathrm{r}$ & 0,27 & 0,45 & 0,48 & 0,77 & 0,72 & & & & & & & & & & & \\
\hline \multirow[t]{2}{*}{ Cec } & $\mathrm{P}$ & 0,01 & 0,05 & 0,01 & 0,01 & 0,03 & 0,01 & & & & & & & & & & \\
\hline & $\mathrm{r}$ & 0,52 & 0,43 & 0,53 & 0,70 & 0,45 & 0,63 & & & & & & & & & & \\
\hline Cic & $\mathrm{P}$ & 0,01 & 0,01 & 0,01 & 0,01 & 0,02 & 0,01 & 0,01 & & & & & & & & & \\
\hline \multirow[t]{2}{*}{ Lg } & $\mathrm{P}$ & 0,03 & 0,01 & 0,01 & 0,01 & 0,01 & 0,01 & 0,01 & 0,01 & 0,90 & 0,01 & & & & & & \\
\hline & $\mathrm{r}$ & 0,46 & 0,58 & 0,54 & 0,74 & 0,73 & 0,68 & 0,62 & 0,55 & 0,03 & 0,88 & & & & & & \\
\hline \multirow[t]{2}{*}{ Lat } & $\mathrm{P}$ & 0,18 & 0,31 & 0,29 & 0,01 & 0,01 & 0,01 & 0,07 & 0,03 & 0,80 & 0,02 & 0,02 & & & & & \\
\hline & $\mathrm{r}$ & 0,30 & 0,23 & 0,24 & 0,67 & 0,71 & 0,57 & 0,40 & $0,46-$ & 0,06 & 0,50 & 0,51 & & & & & \\
\hline \multirow[t]{2}{*}{$\mathrm{La}$} & $\mathrm{P}$ & 0,01 & 0,01 & 0,01 & 0,01 & 0,01 & 0,01 & 0,01 & 0,01 & 0,30 & 0,01 & 0,01 & 0,01 & & & & \\
\hline & $\mathrm{r}$ & 0,56 & 0,69 & 0,62 & 0,60 & 0,58 & 0,66 & 0,56 & $0,63-$ & 0,23 & 0,78 & 0,64 & 0,54 & & & & \\
\hline \multirow[t]{2}{*}{$\mathrm{Pt}$} & $\mathrm{P}$ & 0,07 & 0,08 & 0,12 & 0,03 & 0,59 & 0,35 & 0,03 & 0,16 & 0,95 & 0,02 & 0,01 & 0,68 & 0,16 & & & \\
\hline & $\mathrm{r}$ & 0,40 & 0,39 & 0,35 & 0,46 & 0,12 & 0,21 & 0,46 & $0,31-$ & 0,01 & 0,48 & 0,53 & 0,09 & 0,31 & & & \\
\hline \multirow[t]{2}{*}{ Pet } & $\mathrm{P}$ & 0,01 & 0,01 & 0,01 & 0,01 & 0,01 & 0,01 & 0,01 & 0,01 & 0,66 & 0,01 & 0,01 & 0,01 & 0,01 & 0,08 & & \\
\hline & $\mathrm{r}$ & 0,58 & 0,70 & 0,71 & 0,78 & 0,61 & 0,66 & 0,69 & $0,72-$ & 0,10 & 0,79 & 0,71 & 0,59 & 0,74 & 0,39 & & \\
\hline \multirow[t]{2}{*}{ Pcf } & $\mathrm{P}$ & 0,05 & 0,01 & 0,01 & 0,01 & 0,01 & 0,01 & 0,01 & 0,01 & 0,92 & 0,01 & 0,01 & 0,01 & 0,01 & 0,09 & 0,01 & \\
\hline & $\mathrm{r}$ & 0,43 & 0,59 & 0,63 & 0,95 & 0,88 & 0,83 & 0,74 & $0,74-$ & 0,02 & 0,90 & 0,80 & 0,63 & 0,69 & 0,37 & 0,75 & \\
\hline
\end{tabular}

$\mathrm{Cc}=$ comprimento corporal. $\mathrm{Ap}=$ altura do posterior. $\mathrm{Aa}=$ altura do anterior. Pet = perímetro torácico. $\mathrm{Lp}=$ largura do peito. $\mathrm{Lg}=$ largura da garupa. Cec $=$ comprimento externo da carcaça. Cic $=$ comprimento interno da carcaça $. \mathrm{Cp}=$ comprimento da perna. $\mathrm{Pg}=$ perímetro da garupa. $\mathrm{Lg}=$ largura da garupa. Lat $=$ largura do tórax. La = largura do anterior. $\mathrm{Pt}=$ profundidade do tórax. Pet = perímetro do tórax. Pcf = peso de carcaça fria. Pca = peso corporal ao abate. 
carcaça fria foi o mais alto $(0,93)$ entre as medidas estudadas nesta pesquisa, confirmando os resultados obtidos por Landim et al. (2007), que também constataram maiores valores de correlação entre essas duas variáveis, porém esses resultados foram obtidos com cordeiros.

\section{Conclusões}

As medidas biométricas in vivo e da carcaça de ovelhas de descarte, em sua maioria, são semelhantes, independentemente do estágio fisiológico em que são abatidos os animais. No entanto, o abate de ovelhas logo após o desmame dos seus cordeiros resulta em medidas inferiores para algumas variáveis estudadas. As medidas in vivo (perímetro torácico, largura do peito e da garupa) estão altamente correlacionadas ao peso corporal ao abate e de carcaça fria de ovelhas em diferentes estágios fisiológicos e, também, a algumas características da carcaça, o que permite ao produtor de ovinos utilizar uma dessas medidas como alternativa para estimar o peso médio dos animais sem a necessidade de pesá-los em balança. Sugere-se utilizar a medida do perímetro da garupa para estimar o peso ao abate e de carcaça fria de ovelhas adultas da raça Santa Inês.

\section{Referências}

AZEREDO, D.M.; OSÓRIO, M.T.M.; OSÓRIO, J.C.S. et al. Morfologia in vivo e da carcaça e características produtivas e comerciais em ovinos Corriedale não castrados, castrados e criptorquidas abatidos em diferentes idades. Revista Brasileira de Agrociência, v.12, n.2, p.199-204, 2006.

CUNHA, E.A.; BUENO, M.S.; SANTOS, L.E. Correlações entre características de carcaça de cordeiros Suffolk. In: REUNIÃO ANUAL DA SOCIEDADE BRASILEIRA DE ZOOTECNIA, 36., 1999, Porto Alegre. Anais... Porto Alegre: Sociedade Brasileira de Zootecnia, 1999. (CD-ROM).

EL KARIN, A.I.A.; OWENS, J.B.; WHITAKER, C.J. Measurement on slaughter weight, side weight, carcass joints and their association with composition of two types of Sudan Desert sheep. Journal Agricultural Science, v.110, n.1, p.65-69, 1988.

ENSMinger, M.E. Producción ovina. 2.ed. Buenos Aires: El Ateneo, 1973. 566p.

GARCIA, C.A.; MONTEIRO, A.L.G.; COSTA, C. et al. Medidas objetivas e composição tecidual da carcaça de cordeiros alimentados com diferentes níveis de energia em creep feeding. Revista Brasileira de Zootecnia, v.32, n.6, p.1380-1390, 2003.

LANDIM, A.V.; MARIANTE, A.S.; MCMANUS, C. et al. Características quantitativas da carcaça, medidas morfométricas e suas correlações em diferentes genótipos de ovinos. Ciência Animal Brasileira, v.8, n.4, p.665-676, 2007.

MENDONÇA, G.; OSÓRIO, J.C.; OLIVEIRA, N.M. et al. Morfologia, características da carcaça e componentes do peso vivo em borregos Corriedale e Ideal. Ciência Rural, v.33, n.2, p.351-355, 2003.

MOHAMED, I.D.; AMIN, J.D. Estimating body weight from morphometric measurements of Sahel (Borno White) goats. Small Ruminant Research, v.24, n.1, p.1-5, 1997.

PINHEIRO, R.S.B.; SILVA SOBRINHO, A.G.; MARQUES, C.A.T. et al. Biometría in vivo e da carcaça de cordeiros confinados. Archivos de Zootecnia, v.56 n.216, p.955-958. 2007.

PIRES, C.C.; CARVALHO, S.; GRANDI, A. et al. Características quantitativas e composição tecidual da carcaça de cordeiros terminados em confinamento. Ciência Rural, v.29, n.3, p.539-543, 1999.

REIS, G.L.; ALBUQUERQUE, F.H.M.R.; TEODORO, R.L. et al. Estimativa do peso vivo de novilhas mestiças leiteiras a partir de medidas corporais. In: SIMPÓSIO DA SOCIEDADE BRASILEIRA DE MELHORAMENTO ANIMAL, 5., 2004, Pirassununga. Anais... Pirassununga: Sociedade Brasileira de Melhoramento Animal, 2004.

SANTANA, A.F.; COSTA, G.B.; FONSECA, L.S. Correlações entre peso e medidas corporais em ovinos jovens da raça Santa Inês. Revista Brasileira de Saúde e Produção Animal do Brasil, v.1, n.3, p.74-77, 2001.

SAÑUDO, C.; SIERRA, I. Calidad de la canal en la especie ovina. Ovino, v.1, p.127-153, 1986.

SILVA, L.F.; PIRES, C.C. Avaliações quantitativas e predição das proporções de osso, músculo e gordura da carcaça em ovinos. Revista Brasileira de Zootecnia, v.29, n.4, p.1253-1260, 2000.

SIQUEIRA, E.R.; FERNANDES, S. Efeito do genótipo sobre as medidas objetivas e subjetivas da carcaça de cordeiros terminados em confinamento. Revista Brasileira de Zootecnia, v.29, n.1, p.306-311, 2000.

SIQUEIRA, E.R.; SIMOES, C.D.; FERNANDES, S. Efeito do sexo e do peso ao abate sobre a produção de carne de cordeiro. Morfometria da carcaça, pesos dos cortes, composição tecidual e componentes não constituintes da carcaça. Revista Brasileira de Zootecnia, v.30, n.4, p.1299-1307, 2001.

STATISTICAL ANALYSIS SYSTEM - SAS. Institute SAS/STAT software: changes and enhancements through release 6.12. Cary: SAS Institute, 1997. 1167p.

WOOD, J.D.; MACFIE, H.J.H. The significance of breed in the prediction of lamb carcass composition from fat thickness measurements. Animal Production, v.31, n.3, p.315-319, 1980.

YÁÑEZ, E.A.; RESENDE, K.T.; FERREIRA, A.C.D. et al. Utilização de medidas biométricas para predizer características da carcaça de cabritos Saanen. Revista Brasileira de Zootecnia, v.33, n.6, p.1564-1572, 2004. 